\title{
Interactions between Microtubule-Associated Protein Tau (MAPT) and Small Molecules
}

\author{
Jennifer N. Rauch, Steven H. Olson, and Jason E. Gestwicki \\ Institute for Neurodegenerative Diseases, Weill Institute for Neurosciences, University of California, \\ San Francisco, San Francisco, California 94158 \\ Correspondence: jason.gestwicki@ucsf.edu
}

\begin{abstract}
Tau aggregation is linked to multiple neurodegenerative disorders that are collectively termed tauopathies. Small molecules are powerful probes of the aggregation process, helping to reveal the key steps and serving as diagnostics and reporters. Moreover, some of these small molecules may have potential as therapeutics. This review details how small molecules and chemical biology have helped to elucidate the mechanisms of tau aggregation and how they are being used to detect and prevent tau aggregation. In addition, we comment on how new insights into tau prions are changing the approach to small molecule discovery.
\end{abstract}

\section{INTRODUCTION TO TAU BIOLOGY AND PATHOBIOLOGY}

$M$ icrotubule-associated protein tau (MAPT or tau) is abundantly expressed in neurons and is thought to assist in axonal transport by stabilizing microtubules (Drechsel et al. 1992; Brandt et al. 2005). In humans, tau occurs as six main isoforms generated by alternative splicing of a single gene on chromosome 17. These isoforms contain either three or four repeat domains in their C-terminus (i.e., 3R or $4 \mathrm{R}$ tau), and these repeat domains are responsible for tau's adherence to microtubules (Butner and Kirschner 1991; Mukrasch et al. 2005). Tau is a highly soluble protein, yet it aggregates into insoluble fibers in Alzheimer's disease and other tauopathies. Tau behaves as an intrinsically disordered protein, and various methods have determined it to be largely a random coil in solution (Schweers et al. 1994; Mukrasch et al. 2005; Jeganathan et al. 2008). During aggregation, however, it adopts a cross $\beta$-sheet structure reminiscent of other amyloidogenic proteins (e.g., amyloid- $\beta, \alpha$-synuclein) (von Bergen et al. 2000; Daebel et al. 2012). This conformation allows for non-native interactions between tau monomers, leading to fibrillization (Fig. 1). These fibrils accumulate within neuron cell bodies and dendrites (Brandt et al. 2005; Avila 2006), forming paired-helical filaments (PHFs) that combine into neurofibrillary tangles (NFTs) (Kosik et al. 1986; Lee et al. 1991). Aggregated tau is proteotoxic in model systems, suggesting that oligomeric and/or fibrillar tau may contribute to neurodegeneration (Khlistunova et al. 2006; Lasagna-Reeves et al. 2011). Therefore, it has been suggested that blocking aggregation may halt disease progression (Bulic et al. 2010). Most recently, tau has been found to behave as a prion, passing from cell to cell to propagate its own aggregation (Brunden et al. 2008; Clavaguera et al. 2015; Stancu et al. 2015; see also Holmes and Diamond 2017).

Editor: Stanley B. Prusiner

Additional Perspectives on Prion Diseases available at www.perspectivesinmedicine.org

Copyright (C) 2017 Cold Spring Harbor Laboratory Press; all rights reserved; doi: 10.1101/cshperspect.a024034

Cite this article as Cold Spring Harb Perspect Med 2017;7:a024034 
J.N. Rauch et al.

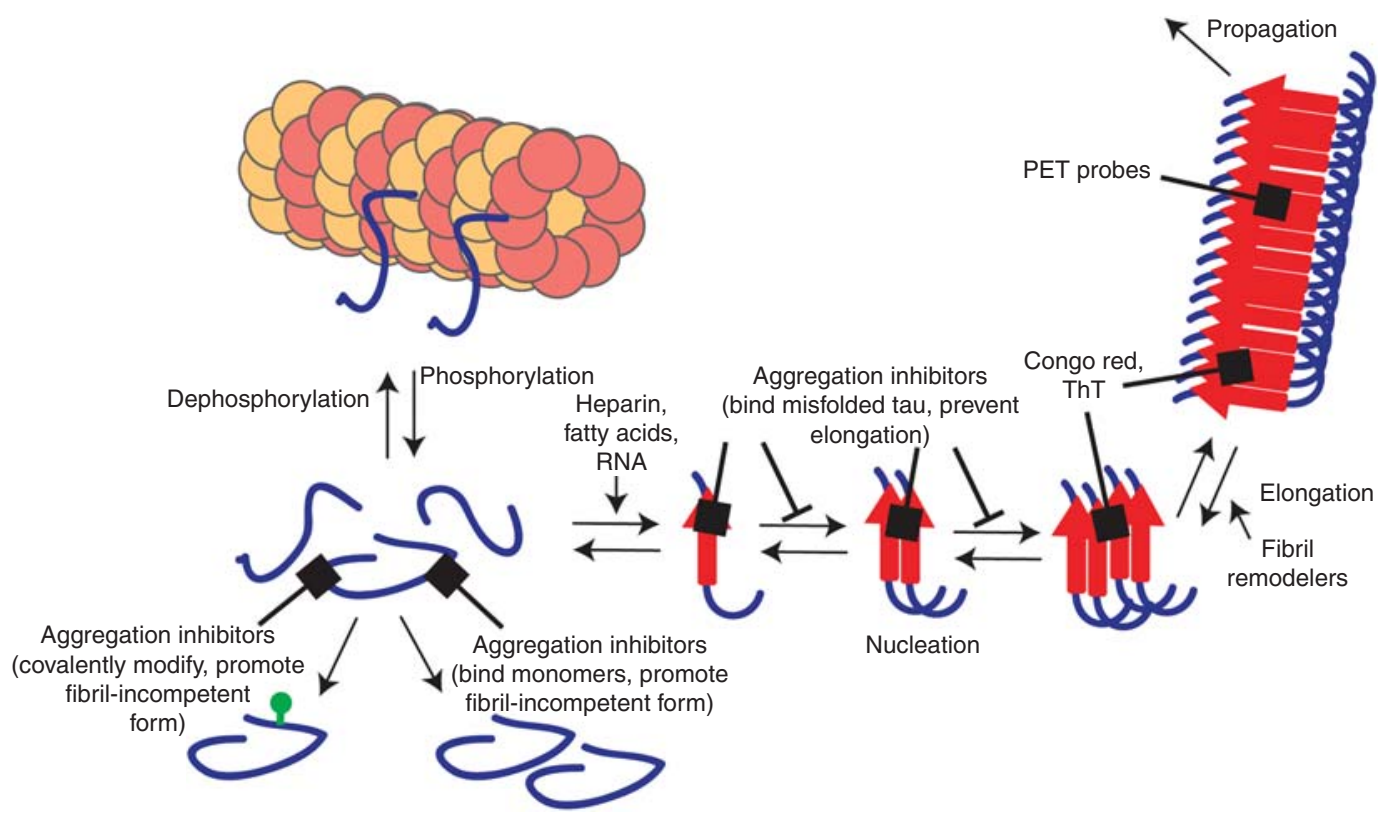

Figure 1. Schematic of tau aggregation highlighting the steps that have been explored using small molecules. Tau released from microtubules assembles into neurofibrillary tangles through a number of poorly characterized nucleation steps. Small molecules have been used as reporters to measure aggregation rates and quantify aggregate deposition in the brain. In addition, small molecules have been used to promote and inhibit aggregation, revealing key steps in the process and suggesting possible ways to treat tauopathies. PET, Positron emission tomography; ThT, thioflavin T.

Tau is subject to multiple types of posttranslational modifications (PTMs), including phosphorylation, proteolytic processing, ubiquitination, glycosylation, nitration, and acetylation (Hanger et al. 2009; Min et al. 2010; Martin et al. 2011; Morris et al 2015). Many of these events appear to impact the localization of tau and its propensity to aggregate. Accordingly, the enzymes responsible for PTMs have emerged as possible drug targets. These efforts have been reviewed elsewhere (Schneider and Mandelkow 2008; Lee et al. 2011). Rather, we focus on how small molecules can directly probe tau aggregation. Molecules that bind directly to tau have been critical in advancing our understanding of how tau aggregates and what features of the protein are important. Indeed, the tau-binding molecules Congo red and thioflavin T (ThT) were essential to the initial discovery and characterization of NFTs, and they play an ongoing role in probing tau structurefunction. In addition, molecules that inhibit tau aggregation or redirect it toward nonfibrillar outcomes have been discovered, and these compounds have revealed key steps in the process. Most recently, tau ligands have advanced as important imaging agents, with the promise of revolutionizing clinical diagnosis of tauopathies. Together, the interactions between tau and small molecules have provided invaluable insight. Yet, challenges remain, and the path toward therapeutics for tauopathies remains uncertain. In this review, we discuss both the successes and failures, with the aim of stimulating new approaches to the discovery of molecules that bind to tau.

\section{AGGREGATION AGONISTS}

Unlike other amyloid-prone proteins, such as amyloid- $\beta$ or $\alpha$-synuclein, efforts to study tau aggregation in vitro initially faced a challenge, as tau would only form fibrils under nonphysiological concentrations and with impractically 
long reaction times (Kosik et al. 1988; Crowther et al. 1994; King et al. 1999). In cellular models, this barrier appeared to be overcome by overexpression, introducing disease-associated mutations/truncations, and/or inducing PTMs (Götz et al. 1995; Duff et al. 2000; Tanemura et al. 2001; Sato et al. 2002). However, a breakthrough came when it was found that purified tau could be made to fibrilize in vitro by the addition of negatively charged cofactors, such as heparin, fatty acids and other lipids, carboxylated microspheres, or RNA (Kampers et al. 1996; Pérez et al. 1996; Hasegawa et al. 1997; Wilson and Binder 1997; Chirita et al. 2005). These accelerants are all anionic, suggesting that mitigating charge repulsion is a critical feature of tau aggregation. Indeed, tau is composed of an acidic $\mathrm{N}$-terminal domain, a middle proline-rich region, and a highly basic C-terminal domain. Under normal conditions, the positive charges in the C-terminal repeat regions are responsible for interacting with a negatively charged region of tubulin (Mukrasch et al. 2005; Sillen et al. 2007). Thus, anionic molecules seem to facilitate tau-tau interactions by attenuating the electrostatic repulsions in the critical C-terminal region (Goedert et al. 1996). This interaction allows for conformational transitions that are known to be essential for tau fibrillogenesis (von Bergen et al. 2000). Once an aggregation nucleus is formed, the fibril can propagate through addition of more monomers (Congdon et al. 2008). This model is made clear by studies using anionic polymers (i.e., lipid micelles). In these systems, tau adopts a $\beta$-sheet structure on the micelle and then aggregates. The speed of this process is dictated by the concentration of negative charges (Chirita and Kuret 2004).

What is the natural aggregation agonist in vivo? RNA and lipid membranes are likely candidates, as both have shown to be potent aggregation inducers in vitro and are known to interact with tau in cells (Brandt et al. 1995; Farah et al. 2006; Violet et al. 2014). Planar molecules, such as thiazine red, have been shown to cause aggregation at high concentrations (Chirita et al. 2005), suggesting that perhaps certain natural metabolites or materials could also spark
Interactions between MAPT and Small Molecules

aggregation under some conditions. Moreover, other factors within the cell, such as oxidative stress, and changes within tau itself, such as PTMs, are expected to influence aggregation in vivo (Avila et al. 2006). For example, some phosphorylations are known to release tau from microtubules, and hyperphosphorylated tau is a major component of PHFs (Hasegawa et al. 1992; Biernat et al. 1993). It is not yet clear whether all aggregation agonists act equally on all tau variants. Further, it remains to be elucidated which natural agonists might be important in the conversion of tau to prions or whether they are involved in the propagation of prion conformers. It is also interesting to speculate that different natural agonists might favor distinct "strains" of tau prions. This seems like an area in which small molecules might play important roles in the future.

\section{AGGREGATION REPORTERS}

Like other amyloid-prone proteins, tau adopts a conformation consisting of parallel, in-register $\beta$-sheets oriented perpendicular to the filament axis. The structural similarity between tau and other amyloidogenic proteins is convenient because several fluorescent ligands previously discovered as aggregation reporters for other amyloidogenic proteins (Vassar and Culling 1959; Kelenyi 1967; Naiki et al. 1989) have also proven useful in studying tau. A common feature of these molecules is that they undergo a change in fluorescence intensity or a Stokes shift in excitation and/or emission optima when bound to $\beta$-sheet-rich aggregates (LeVine 1993). Molecules such as ThT, thioflavin $S$ (ThS), and Congo red have become essential probes, finding a place in nearly every study of tau aggregation. For example, one important use of these probes is in high-throughput screening (HTS). Screening strategies typically follow a general workflow in which tau (or just the repeat region of tau) is incubated overnight with an inducer (e.g., heparin) and a probe (e.g., ThT). Molecules able to limit ThT fluorescence are then selected as aggregation inhibitors, as discussed in more detail below. It is important to note that these probes may not be mechanis- 
J.N. Rauch et al.

tically innocent bystanders in aggregation; recent reports associate ThTwith accelerated rates of fibrillization for amyloid- $\beta$ and $\alpha$-synuclein (Coelho-Cerqueira et al. 2014; Di Carlo et al. 2015).

What molecular features of tau fibrils are recognized by ThTand other probes? This question has been extensively studied in other amyloid systems (Reinke and Gestwicki 2011). For example, in the case of amyloid- $\beta$, Phe residues in the core of the $\beta$-sheet have been shown to make critical hydrophobic contacts with the probe (Biancalana et al. 2009). In the bound configuration, the reporter often lies perpendicular to the peptide chain and in line with the fiber axis (Klunk et al. 1994; Lockhart et al. 2005). For example, Congo red is proposed to span across five peptide chains based on the distances between the sulfonic groups (Klunk et al. 1989, 1994). In addition to this configuration, spectroscopic experiments have shown that amyloid fibrils have multiple, nonequivalent binding sites. Indeed, ThT has been shown to populate up to three different binding sites on amyloid- $\beta$ fibrils (LeVine 2005; Lockhart et al. 2005). Two binding sites are thought to occur once every four to 35 monomers, and the last binding site is only predicted to occur once per approximately 300 monomers. Congo red shares one of ThT's high-density binding sites, but also has a weak discrete binding site of its own on the end of the fibril in an orientation parallel to the $\beta$-sheets (Ye et al. 2005). Although these studies with Congo red and ThT have revealed much about the structure of amyloid- $\beta$ fibrils, there have not been many equivalent structural investigations of tau fibrils. This need is particularly pressing because tau appears to have unique structural features. For example, in the case of Orange $G$, hydrophobic interactions with the amyloid- $\beta$ core sequence (KLVFFA) are necessary, whereas binding of the same molecule to tau is reliant on polar interactions with core Gln and Lys residues (VQIVYK) (Landau et al. 2011). Similarly, the Kuret group found that the electronic properties of ThT-inspired ligands are important for displacing ThS from tau fibrils (Cisek et al. 2012). Differences between amyloid- $\beta$ and tau are also observed when oligomers are studied. For example, ThT/Congo red can bind amyloid- $\beta$ oligomers but not small tau oligomers (Maezawa et al. 2008; Lasagna-Reeves et al. 2010). Again, it has been shown that aromatic residues in the amyloid- $\beta$ sequence are critical for ThT oligomer binding (Wolfe et al. 2010). One group has exploited the polarity differences in the binding pocket to create conjugated oligothiophenes that become luminescent in the presence of amyloids. By altering the position of anionic groups on the oligothiophenes, these molecules can discriminate between tau and amyloid- $\beta$ deposits (Klingstedt et al. 2015). Further work may develop these molecules into diagnostic agents that could be used to detect specific tau aggregates.

\section{AGGREGATION INHIBITORS}

The exact pathway by which neurons are lost in tauopathies is still poorly understood. However, there is a general consensus that protein aggregation is a major element of toxicity, and therefore tau aggregation inhibitors could have potential as drugs. Where should these molecules bind? ThT and Congo red, which by analogy to amyloid- $\beta$, likely bind in the side-chain grooves formed perpendicular to the peptide chains, are typically very poor tau aggregation inhibitors and in some cases can accelerate aggregation. This makes some sense in that the molecules are binding to fibrils that have already formed and are not interfering with the critical templating process. Rather, aggregation inhibitors that bind parallel to the peptides would be expected to directly disrupt templating. The challenge is that the highly polar local environment of the terminal tau peptide in its $\beta$-strand conformation is expected to be a difficult drug target. Some clues for better binding sites might come from studies on mutations and PTMs that impact tau aggregation. For example, mutations in the repeat regions of tau $(\mathrm{G} 272 \mathrm{~V}, \mathrm{P} 301 \mathrm{~L})$ have been shown to speed the nucleation reaction rate and lower the minimal concentration necessary to support aggregation (Chang et al. 2008). Such studies might point to strategic binding sites for small molecule inhibitors, although the lack of 
structural information on the tau oligomers has slowed progress.

In the absence of structure-based design, a number of laboratories have taken an unbiased HTS strategy. In these experiments, full-length tau or shorter tau fragments are assembled into fibrils in vitro, and compound collections are screened for inhibitors. Several platforms have been used, including ThT-based assays (as described above), filter assays to measure soluble versus insoluble tau, transmission electron microscopy to look at filament length/amount, and fluorescence polarization (FP) assays using labeled tau (Pickhardt et al. 2005; Taniguchi et al. 2005; Chang et al. 2009; Crowe et al. 2009). Using these methods, more than 400 aggregation inhibitors have been reported. Most of these are planar heterocycles, such as aminothienopyridazines, quinoxalines, benzothiazoles, rhodanines, anthraquinones, porphyrins, phenylthiahydrazides, and $N$-phenylamines (Necula et al. 2005; Pickhardt et al. 2005, 2007a; Taniguchi et al. 2005; Chang et al. 2009; Crowe et al. 2007, 2009). In most cases, mechanistic studies are lacking and structureactivity relationships (SARs) are not available, so it is difficult to judge how the molecules are acting or whether they can be optimized beyond the screening "hit." To make matters worse, a few of the reported molecules are likely to be competitive inhibitors of ThT or Congo red, potentially serving as false positives. Other molecules might be expected to block the activity of the accelerant (e.g., heparin), another type of artifact. However, some of these compounds may indeed recognize critical residues involved in tau self-assembly. Indeed, a few classes of inhibitors have been explored in more detail, revealing mechanisms of tau aggregation and its inhibition.

One of the first compounds identified was the phenothiazine, methylene blue (MB; methylthioninium chloride) (Wischik et al. 1996). This compound was shown to partially disrupt the structure of isolated PHFs, and subsequent studies showed that MB could prevent tau aggregation in vitro (Wischik et al 1996; Taniguchi et al. 2005). Treatment with MB or its analogs has also been shown to reduce tau-reactive neu-
Interactions between MAPT and Small Molecules

rons and reverse spatial and motor deficits in multiple transgenic mouse models (O'Leary et al. 2010; Congdon et al. 2012; Melis et al. 2015). A phase II clinical trial of MB in mild/moderate $\mathrm{AD}$ has been completed, and $\mathrm{MB}$ was found to promote stabilization of $\mathrm{AD}$ over a period of 50 weeks in some patients (Wischik et al. 2015). Currently, a phase III clinical trial is underway with a stable, reduced version of $\mathrm{MB}$, LMTX, and results should be available starting in 2016 (Wischik et al. 2014). MB is well known to be redox active, so it is not surprising that its ability to block aggregation involves oxidization of cysteine residues important for aggregation (Akoury et al. 2013b; Crowe et al. 2013). Indeed, alanine mutations of Cys291 and Cys322 or the addition of reducing agents, such as dithiothreitol or glutathione, block MB's antiaggregation activity (Akoury et al. 2013b; Crowe et al. 2013). Because the MB drug levels measured during in vivo efficacy experiments are lower than the concentrations required to oxidize the key tau cysteines, it is not known whether this mechanism of action is relevant in vivo (Baddeley et al. 2015). Both the promiscuous nature of MB's redox activity and the high concentration of glutathione in the liver add to the uncertainty. Recently, MB was shown to cause dissolution of PHFs isolated from AD brain tissue with a binding affinity consistent with both the trough brain concentrations observed in mouse efficacy studies and the most effective dose in the human phase II clinical trial (Harrington et al. 2015). Regardless of the mechanism, this small molecule remains the most advanced of the known aggregation inhibitors.

Chemical modification of tau, as has been shown for $\mathrm{MB}$, has been observed in other programs. For example, aminothienopyridazines (ATPZs) have been shown to oxidize cysteine residues on tau to prevent its aggregation (Crowe et al. 2013). Likewise, the natural product oleocanthal creates covalent adducts with lysine residues in tau. This modification prevents tau aggregation, presumably by neutralizing lysine-positive charges in the repeat domain (Li et al. 2009). None of these activities are likely to be specific for tau, complicating their use in cells or animals (at least as mechanistic probes). 
J.N. Rauch et al.

However, covalent binding is becoming an increasingly common approach in drug discovery (Mah et al. 2014; Bauer 2015), so there may be opportunities for taking advantage of this mechanism.

Polyphenols, including EGCG (epigallocatechin gallate), myrectin, and tannic acid, have all been found to prevent tau aggregation with half-maximal inhibitory concentration $\left(\mathrm{IC}_{50}\right)$ values in the low to submicromolar range ( $\mathrm{Ta}$ niguchi et al. 2005; Yao et al. 2013). These molecules are "frequent hitters," with notoriously promiscuous protein-binding properties. However, despite their severe disadvantages as therapeutics or probes in cells and animals, the polyphenols appear to be useful mechanistic tools in vitro. EGCG was hypothesized to prevent tau aggregation by binding misfolded monomers, thus preventing the conversion of tau into an aggregation-prone form (Wobst et al. 2015). Consistent with this idea, polyphenols are not effective at disaggregating preformed tau fibrils (Taniguchi et al. 2005). Caution should be used when interpreting studies using polyphenol-containing molecules. Catechols, catecholamines, and polyphenols are rapidly oxidized in solution to quinones. These species efficiently quench ThT fluorescence and are potentially false positives in many assays (Coelho-Cerqueira et al. 2014). Furthermore, some flavonoids, including myricetin, are believed to derive their promiscuous activity from their ability to form aggregates at micromolar concentrations (Tritsch et al. 2015). If a more drug-like scaffold could access this type of chemical chaperone activity as proposed for EGCG, it could have powerful implications. In particular, such molecules might have a profound effect on tau prion conversion by limiting access to monomers. Such an approach was recently reported for $\alpha$-synuclein and transthyretin (Bulawa et al. 2012; Tóth et al. 2014).

As mentioned previously, a number of other compounds have been reported as inhibitors of tau aggregation, and mechanistic and translational studies are underway. For example, benzofurazans such as TRV-1387 (Reed et al. 2015) are proposed to inhibit the aggregation of tau and amyloid- $\beta$ as measured by ThS and ThT binding, respectively. Related molecules are reported to show a reduction of tau and amyloid$\beta$ oligomers in transgenic mouse models of Alzheimer's disease (Treventis Corporation 2015). Finally, Oligomerix described TO-330, a small molecule inhibitor of tau oligomerization; dose-response data show that TO-330 behaves similarly to $\mathrm{MB}$. The structure has not been disclosed, and they propose to advance the series to hit optimization (Moe 2013).

\section{TAU FIBRIL REMODELING}

Numerous compounds have been reported to remodel tau fibrils. For example, the Mandelkow group performed HTS of 200,000 compounds using both inhibition of tau aggregation and disassembly of tau aggregates as criteria for hit selection (Pickhardt et al. 2005). In some of these cases, medicinal chemistry campaigns have produced informative SARs and advanced the potency of the compounds (Bulic et al. 2007; Larbig et al. 2007; Pickhardt et al. $2007 a, b)$. For a number of these chemical series, hydrogen bonds seemed to play a predominant role, where preference for nitro groups, carboxylic acids, phenols, and sulfonamides are enriched. In the case of the rhodanine-based inhibitors, SAR-driven optimization led to submicromolar potencies for both aggregation inhibition and disassembly and, importantly, showed reduced toxicity in an N2a cell model (Fig. 2) (Bulic et al. 2007). Furthermore, this molecule (bb14) was shown to be active in a Caenorhabditis elegans model (Fatouros et al. 2012) and in organotypic slice culture models (Messing et al. 2013). Despite these advances, a detailed mechanistic understanding of how these molecules and other fibril remodelers interact with tau is still lacking. For one class of molecules (phenylthiazolyhydrazides), nuclear magnetic resonance (NMR) experiments showed that the molecule binds to the repeat regions of tau (Pickhardt et al. 2007a), suggesting that it might directly compete with selfassembly. Other small molecules, such as the benzothiazole N744, seem to inhibit tau filament extension but not nucleation (Chirita and Kuret 2004; Necula et al. 2005). Interestingly, 
Interactions between MAPT and Small Molecules

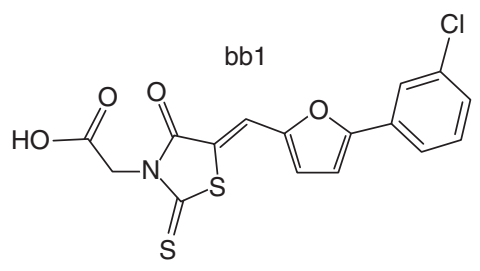

$\mathrm{IC}_{50}: 0.82 \mu \mathrm{M}, \mathrm{DC}_{50}: 0.10 \mu \mathrm{M}$

Inhibition of cellular tau aggregation: $20 \% \pm 5 \%$

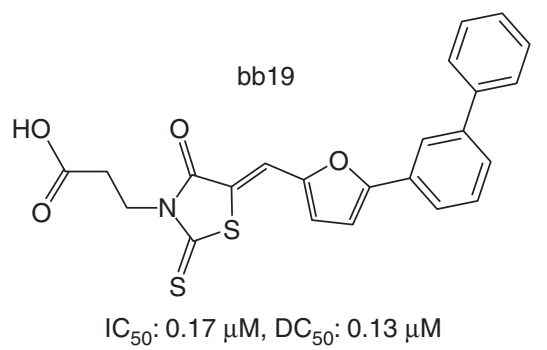

Inhibition of cellular tau aggregation: $16 \% \pm 4 \%$

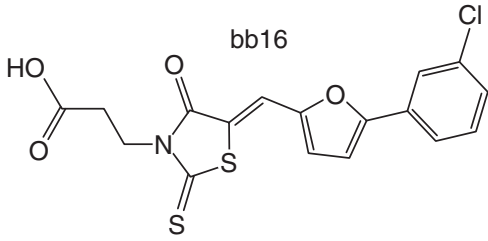

$\mathrm{IC}_{50}: 0.47 \mu \mathrm{M}, \mathrm{DC}_{50}: 0.30 \mu \mathrm{M}$

Inhibition of cellular tau aggregation: $21 \% \pm 13 \%$

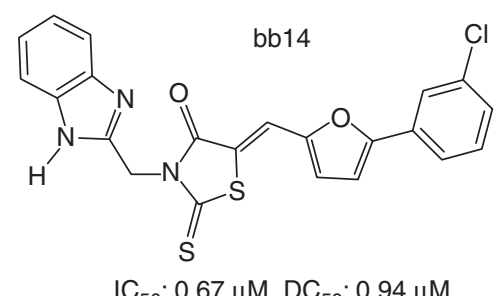

Inhibition of cellular tau aggregation: $70 \% \pm 4 \%$

Figure 2. Summary of the structure-activity relationships for tau aggregation inhibitors.

this compound and certain other dye-like molecules form aggregates at higher concentrations that enhance tau fibrillization (Congdon et al. 2007). However, such compounds provide another novel mechanism for future exploration.

Small oligomers of tau appear to pose the highest neurotoxic threat (Lasagna-Reeves et al. 2011). Therefore, compounds that remodel tau fibrils into smaller oligomers may be less helpful than originally thought. For example, porphyrins and cyanines have both been shown to stabilize SDS-soluble, oligomeric tau (Akoury et al. 2013b; Schafer et al. 2013). Although the toxicity of these structures is still unclear, some insights might be gained from studies on other amyloidprone proteins, such as Sup35. Specifically, it has been shown that small molecules can promote specific Sup35 conformers, leading to strain resistance and necessitating multiple drug combinations for eradication (Roberts et al. 2009).

\section{PET PROBES}

Clinical diagnosis of tauopathies is currently hindered by the lack of definitive diagnostic methods to detect NFTs in living subjects. Molecular imaging tools, such as positron emission tomography (PET), hold promise as a way to detect disease. Three different PET tracers are currently approved by the Food and Drug Administration (FDA) to detect amyloid- $\beta$ deposits (Amyvid; florbetapir F-18, Vizamyl; flutametamol F-18, Neuaceg; florbetaben F18). Likewise, at least seven tau pathology PET tracers are under development: C-11 PBB3, F-18 THK-523, F-18 THK-5105, F-18 THK-5117, F-18 FDDNP, F-18 T807 (now AV1451), and F-18 T808 (Fig. 3) (Agdeppa et al. 2001; Fodero-Tavoletti et al. 2011; Zhang et al. 2012; Maruyama et al. 2013; Okamura et al. 2013; Xia et al. 2013). Not all of these agents are specific for tau. For instance, F-18 FDDNP binds to both amyloid- $\beta$ and tau pathologies with relatively weak affinity (Thompson et al. 2009). THK-523 has affinity for tau lesions only in $\mathrm{AD}$ brains, but not tau lesions from other tauopathies (Fodero-Tavoletti et al. 2014). Further, this tracer also displayed elevated white matter binding, making it unsuitable for future clinical settings (Villemagne et al. 2014). The failure of THK-523, however, led to the development of THK-5105 and THK-5117, which have both shown to have greater specificity for tau as well as better toxicity profiles (Okamura et al. 
J.N. Rauch et al.<smiles>CC(=C(C#N)C#N)c1ccc2cc(N(C)CCC(F)F)ccc2c1</smiles><smiles>Nc1ccc(-c2ccc3cc(OCCF)ccc3n2)cc1</smiles>
F-18 THK-523<smiles>[4H]CC(O)COc1ccc2nc(-c3ccc(N(C)C)cc3)ccc2c1</smiles><smiles>CNc1ccc(-c2ccc3cc(OCC(O)CF)ccc3n2)cc1</smiles>

F-18 THK-5105

F-18 THK-5117<smiles>CC(C)C(C(F)(F)F)C(F)(F)c1ccc(-c2ccc3c(c2)[nH]c2ccncc23)cn1</smiles>

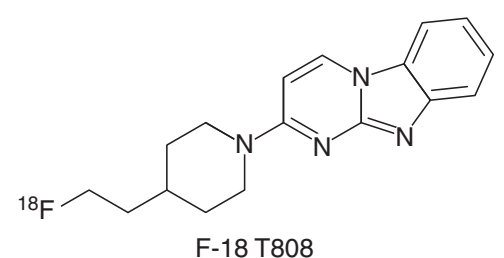<smiles>CCCCCCCCCCCCCCC=CC=Cc1ccc(NC)nc1</smiles>

Figure 3. Chemical structures of tau-binding positron emission tomography (PET) probes.

2013). Clinical studies on these molecules are ongoing.

The benzoimidazopyrimidines $\mathrm{T} 808$ and T807/AV1451 and the benzothiazole PBB3 also have promise for the imaging of tau. T807/AV1451 is currently in phase II development and has shown a 29-fold preference for tau aggregates over amyloid- $\beta$ (Chien et al. 2013). In addition, T807 and T808 molecules displayed rapid brain uptake followed by a rapid washout in normal mice, suggesting low nonspecific binding (Zhang et al. 2012; Xia et al. 2013). In patients with mild cognitive impairment and $\mathrm{AD}$ subjects, a distinct pattern of tracer uptake was observed relative to the cerebellum, mirroring the current understanding of tau deposition as described by Braak and Braak (Chien et al. 2013, 2014). Despite these exciting advances, little is known about where these probes bind or why they have selectivity for tau pathology versus other amyloids.

\section{FUTURE CONSIDERATIONS}

Tau aggregation is an established marker and potential mediator of neurodegenerative tauopathies. Small molecules that bind to tau have taught us many lessons about the aggregation process, as well as helped us to delineate potential means of therapy. However, our knowledge is far from complete. What specific regions of tau do these molecules bind, and do 
they force any structural constraints on tau itself? Do they bind tau before or after aggregation? With this understanding, we may gain insight into how to specifically target tau.

Interestingly, a majority of tau inhibitors have been discovered in HTS efforts using just the repeat regions of tau and without any PTMs or disease-associated mutations. Indeed, it is known that phosphorylation and mutation play a key role in aggregation kinetics (Chang et al. 2011; Combs and Gamblin 2012), suggesting that some molecules may be more or less effective at preventing their aggregation. We suggest that future efforts might better integrate knowledge of disease-associated variations to focus small molecule discovery campaigns.

One of the largest untapped areas of discovery involves the realization that tau, and many other amyloid-prone proteins, have features in common with prions. Specifically, tau is able to pass from cell to cell and spread the aggregated form. These are paradigm-shifting observations, from the point of view of small molecule discovery. What effect do small molecules have on tau prion formation, clearance, or conversion? Can the process of prion templating provide an entirely new source of drug targets? One can speculate that a small molecule might bind to tau and alter the energetic landscape to raise the barriers between tau prion formation and/ or the infection of other tau monomers. In addition, one can envision that small molecules might bind to tau prions in the extracellular space to block their entry into adjacent cells or otherwise alter their ability to spread. Further, small molecules might bind tau prions inside of cells and either accelerate their turnover or change their trafficking. Any of these (wildly speculative) mechanisms might create new opportunities for discovery. A key will be to design HTS campaigns to take into account this emerging biology and to continue the development of sensitive chemical probes for studying this process.

Finally, the development of small molecules that bind to tau is severely hindered by a lack of structural information. NMR is a powerful way to study tau monomers in solution (Mukrasch
Interactions between MAPT and Small Molecules

et al. 2009) and electron microscopy has begun to show the structures of fibrils (Combs and Gamblin 2012), yet we still have little understanding of how tau prions or oligomers form or what they look like. Because of the heterogeneity of tau aggregates, classical structural methods have difficulty uncovering the nature of these structures. To unlock the full potential of modern structure-based drug discovery, we must better understand the binding sites, the relationships between these sites, and the structural dynamics of tau.

Small molecules will continue to be one important tool in the arsenal for studying tau. These compounds can report on tau aggregation in vitro and in vivo. They can also be used to study the requirements for tau aggregation in more detail, as revealed by the compounds that oxidize tau's cysteines. Finally, these compounds might be the starting point for therapies that act directly on tau aggregation, the key physical event that is linked to disease.

\section{ACKNOWLEDGMENTS}

This work is supported by the National Institutes of Health (NS059690).

\section{REFERENCES}

${ }^{*}$ Reference is also in this collection.

Agdeppa ED, Kepe V, Liu J, Flores-Torres S, Satyamurthy N, Petric A, Cole GM, Small GW, Huang SC, Barrio JR. 2001. Binding characteristics of radiofluorinated 6-dialkylamino-2-naphthylethylidene derivatives as positron emission tomography imaging probes for $\beta$-amyloid plaques in Alzheimer's disease. J Neurosci 21: RC189.

Akoury E, Gajda M, Pickhardt M, Biernat J, Soraya P, Griesinger C, Mandelkow E, Zweckstetter M. 2013a. Inhibition of tau filament formation by conformational modulation. J Am Chem Soc 135: 2853-2862.

Akoury E, Pickhardt M, Gajda M, Biernat J, Mandelkow E, Zweckstetter M. 2013b. Mechanistic basis of phenothiazine-driven inhibition of Tau aggregation. Angew Chem Int Ed Engl 52: 3511-3515.

Avila J. 2006. Tau protein, the main component of paired helical filaments. J Alzheimers Dis 9: 171-175.

Avila J, Santa-María I, Pérez M, Hernández F, Moreno F. 2006. Tau phosphorylation, aggregation, and cell toxicity. J Biomed Biotechnol 2006: 74539.

Baddeley TC, McCaffrey J, Storey JM, Cheung JK, Melis V Horsley D, Harrington CR, Wischik CM. 2015. Complex disposition of methylthioninium redox forms deter- 
J.N. Rauch et al.

mines efficacy in tau aggregation inhibitor therapy for Alzheimer's disease. J Pharmacol Exp Ther 352: 110-118.

Bauer RA. 2015. Covalent inhibitors in drug discovery: From accidental discoveries to avoided liabilities and designed therapies. Drug Discov Today 20: 1061-1073.

Biancalana M, Makabe K, Koide A, Koide S. 2009. Molecular mechanism of thioflavin- $T$ binding to the surface of $\beta$-rich peptide self-assemblies. J Mol Biol 385: 10521063.

Biernat J, Gustke N, Drewes G, Mandelkow EM, Mandelkow E. 1993. Phosphorylation of $\mathrm{Ser}^{262}$ strongly reduces binding of tau to microtubules: Distinction between PHF-like immunoreactivity and microtubule binding. Neuron 11: $153-163$.

Brandt R, Leger J, Lee G. 1995. Interaction of tau with the neural plasma membrane mediated by tau's amino-terminal projection domain. J Cell Biol 131: 1327-1340.

Brandt R, Hundelt M, Shahani N. 2005. Tau alteration and neuronal degeneration in tauopathies: Mechanisms and models. Biochim Biophys Acta 1739: 331-354.

Brunden KR, Trojanowski JQ, Lee VM. 2008. Evidence that non-fibrillar tau causes pathology linked to neurodegeneration and behavioral impairments. J Alzheimers Dis 14: 393-399.

Bulawa CE, Connelly S, Devit M, Wang L, Weigel C, Fleming JA, Packman J, Powers ET, Wiseman RL, Foss TR, et al. 2012. Tafamidis, a potent and selective transthyretin kinetic stabilizer that inhibits the amyloid cascade. Proc Natl Acad Sci 109: 9629-9634.

Bulic B, Pickhardt M, Khlistunova I, Biernat J, Mandelkow EM, Mandelkow E, Waldmann H. 2007. Rhodaninebased tau aggregation inhibitors in cell models of tauopathy. Angew Chem Int Ed Engl 46: 9215-9219.

Bulic B, Pickhardt M, Mandelkow EM, Mandelkow E. 2010. Tau protein and tau aggregation inhibitors. Neuropharmacology 59: 276-289.

Butner KA, Kirschner MW. 1991. Tau protein binds to microtubules through a flexible array of distributed weak sites. J Cell Biol 115: 717-730.

Chang E, Kim S, Yin H, Nagaraja HN, Kuret J. 2008. Pathogenic missense MAPT mutations differentially modulate tau aggregation propensity at nucleation and extension steps. J Neurochem 107: 1113-1123.

Chang E, Congdon EE, Honson NS, Duff KE, Kuret J. 2009. Structure-activity relationship of cyanine tau aggregation inhibitors. J Med Chem 52: 3539-3547.

Chang E, Kim S, Schafer KN, Kuret J. 2011. Pseudophosphorylation of tau protein directly modulates its aggregation kinetics. Biochim Biophys Acta 1814: 388-395.

Chien DT, Szardenings AK, Bahri S, Walsh JC, Mu F, Su MY, Shankle WR, Elizarov A, Kolb HC. 2013. Early clinical PET imaging results with the novel PHF-tau radioligand [F-18]-T807. J Alzheimers Dis 34: 457-468.

Chien DT, Szardenings AK, Bahri S, Walsh JC, Mu F, Xia C, Shankle WR, Lerner AJ, Su MY, Elizarov A, et al. 2014. Early clinical PET imaging results with the novel PHF-tau radioligand [F18]-T808. J Alzheimers Dis 38: 171-184.

Chirita CN, Kuret J. 2004. Evidence for an intermediate in tau filament formation. Biochemistry 43: 1704-1714.
Chirita CN, Congdon EE, Yin H, Kuret J. 2005. Triggers of full-length tau aggregation: A role for partially folded intermediates. Biochemistry 44: 5862-5872.

Cisek K, Jensen JR, Honson NS, Schafer KN, Cooper GL, Kuret J. 2012. Ligand electronic properties modulate tau filament binding site density. Biophys Chem 170: 25-33.

Clavaguera F, Hench J, Goedert M, Tolnay M. 2015. Invited review: Prion-like transmission and spreading of tau pathology. Neuropathol Appl Neurobiol 41: 47-58.

Coelho-Cerqueira E, Pinheiro AS, Follmer C. 2014. Pitfalls associated with the use of Thioflavin-T to monitor antifibrillogenic activity. Bioorg Med Chem Lett 24: $3194-$ 3198.

Combs B, Gamblin TC. 2012. FTDP-17 tau mutations induce distinct effects on aggregation and microtubule interactions. Biochemistry 51: 8597-8607.

Congdon EE, Necula M, Blackstone RD, Kuret J. 2007. Potency of a tau fibrillization inhibitor is influenced by its aggregation state. Arch Biochem Biophys 465: 127-135.

Congdon EE, Kim S, Bonchak J, Songrug T, Matzavinos A, Kuret J. 2008. Nucleation-dependent tau filament formation: The importance of dimerization and an estimation of elementary rate constants. J Biol Chem 283: 1380613816.

Congdon EE, Wu JW, Myeku N, Figueroa YH, Herman M, Marinec PS, Gestwicki JE, Dickey CA, Yu WH, Duff KE. 2012. Methylthioninium chloride (methylene blue) induces autophagy and attenuates tauopathy in vitro and in vivo. Autophagy 8: 609-622.

Crowe A, Ballatore C, Hyde E, Trojanowski JQ, Lee VM. 2007. High throughput screening for small molecule inhibitors of heparin-induced tau fibril formation. Biochem Biophys Res Commun 358: 1-6.

Crowe A, Huang W, Ballatore C, Johnson RL, Hogan AM, Huang R, Wichterman J, McCoy J, Huryn D, Auld DS, et al. 2009. Identification of aminothienopyridazine inhibitors of tau assembly by quantitative high-throughput screening. Biochemistry 48: 7732-7745.

Crowe A, James MJ, Lee VM, Smith AB III, Trojanowski JQ, Ballatore C, Brunden KR. 2013. Aminothienopyridazines and methylene blue affect Tau fibrillization via cysteine oxidation. J Biol Chem 288: 11024-11037.

Crowther RA, Olesen OF, Smith MJ, Jakes R, Goedert M. 1994. Assembly of Alzheimer-like filaments from fulllength tau protein. FEBS Lett 337: 135-138.

Daebel V, Chinnathambi S, Biernat J, Schwalbe M, Habenstein B, Loquet A, Akoury E, Tepper K, Müller H, Baldus $\mathrm{M}$, et al. 2012. $\beta$-Sheet core of tau paired helical filaments revealed by solid-state NMR. J Am Chem Soc 134: 13982 13989.

Di Carlo MG, Minicozzi V, Foderà V, Militello V, Vetri V, Morante S, Leone M. 2015. Thioflavin T templates amyloid $\beta(1-40)$ conformation and aggregation pathway. Biophys Chem 206: 1-11.

Drechsel DN, Hyman AA, Cobb MH, Kirschner MW. 1992. Modulation of the dynamic instability of tubulin assembly by the microtubule-associated protein tau. Mol Biol Cell 3: 1141-1154.

Duff K, Knight H, Refolo LM, Sanders S, Yu X, Picciano M, Malester B, Hutton M, Adamson J, Goedert M, et al. 2000. Characterization of pathology in transgenic mice 
over-expressing human genomic and cDNA tau transgenes. Neurobiol Dis 7: 87-98.

Farah CA, Perreault S, Liazoghli D, Desjardins M, Anton A, Lauzon M, Paiement J, Leclerc N. 2006. Tau interacts with Golgi membranes and mediates their association with microtubules. Cell Motil Cytoskeleton 63: 710-724.

Fatouros C, Pir GJ, Biernat J, Koushika SP, Mandelkow E, Mandelkow EM, Schmidt E, Baumeister R. 2012. Inhibition of tau aggregation in a novel Caenorhabditis elegans model of tauopathy mitigates proteotoxicity. Hum Mol Genet 21: 3587-3603.

Fodero-Tavoletti MT, Okamura N, Furumoto S, Mulligan RS, Connor AR, McLean CA, Cao D, Rigopoulos A, Cartwright GA, O'Keefe G, et al. 2011. ${ }^{18}$ F-THK523: A novel in vivo tau imaging ligand for Alzheimer's disease. Brain 134: $1089-1100$

Fodero-Tavoletti MT, Furumoto S, Taylor L, McLean CA, Mulligan RS, Birchall I, Harada R, Masters CL, Yanai K, Kudo Y, et al. 2014. Assessing THK523 selectivity for tau deposits in Alzheimer's disease and non-Alzheimer's disease tauopathies. Alzheimers Res Ther 6: 11.

Goedert M, Jakes R, Spillantini MG, Hasegawa M, Smith MJ, Crowther RA. 1996. Assembly of microtubule-associated protein tau into Alzheimer-like filaments induced by sulphated glycosaminoglycans. Nature 383: 550-553.

Götz J, Probst A, Spillantini MG, Schäfer T, Jakes R, Bürki K, Goedert M. 1995. Somatodendritic localization and hyperphosphorylation of tau protein in transgenic mice expressing the longest human brain tau isoform. $E M B O$ J 14: 1304-1313.

Hanger DP, Anderton BH, Noble W. 2009. Tau phosphorylation: The therapeutic challenge for neurodegenerative disease. Trends Mol Med 15: 112-119.

Harrington CR, Storey JM, Clunas S, Harrington KA, Horsley D, Ishaq A, Kemp SJ, Larch CP, Marshall C, Nicoll SL, et al. 2015. Cellular models of aggregation-dependent template-directed proteolysis to characterize Tau aggregation inhibitors for treatment of Alzheimer disease. J Biol Chem 290: 10862-10875.

Hasegawa M, Morishima-Kawashima M, Takio K, Suzuki M, Titani K, Ihara Y. 1992. Protein sequence and mass spectrometric analyses of tau in the Alzheimer's disease brain. J Biol Chem 267: 17047-17054.

Hasegawa M, Crowther RA, Jakes R, Goedert M. 1997. Alzheimer-like changes in microtubule-associated protein Tau induced by sulfated glycosaminoglycans. Inhibition of microtubule binding, stimulation of phosphorylation, and filament assembly depend on the degree of sulfation. J Biol Chem 272: 33118-33124.

* Holmes BB, Diamond MI. 2017. Cellular models for the study of prions. Cold Spring Harb Perspect Med 7: a024026.

Jeganathan S, von Bergen M, Mandelkow EM, Mandelkow E. 2008. The natively unfolded character of tau and its aggregation to Alzheimer-like paired helical filaments. Biochemistry 47: 10526-10539.

Kampers T, Friedhoff P, Biernat J, Mandelkow EM, Mandelkow E. 1996. RNA stimulates aggregation of microtubule-associated protein tau into Alzheimer-like paired helical filaments. FEBS Lett 399: 344-349.
Kelenyi G. 1967. Thioflavin S fluorescent and Congo red anisotropic stainings in the histologic demonstration of amyloid. Acta Neuropathol 7: 336-348.

Khlistunova I, Biernat J, Wang Y, Pickhardt M, von Bergen M, Gazova Z, Mandelkow E, Mandelkow EM. 2006. Inducible expression of Tau repeat domain in cell models of tauopathy: Aggregation is toxic to cells but can be reversed by inhibitor drugs. J Biol Chem 281: 1205-1214.

King ME, Ahuja V, Binder LI, Kuret J. 1999. Ligand-dependent tau filament formation: Implications for $\mathrm{Alz}$ heimer's disease progression. Biochemistry 38: 1485114859.

Klingstedt T, Shirani H, Mahler J, Wegenast-Braun BM, Nyström S, Goedert M, Jucker M, Nilsson KP. 2015. Distinct spacing between anionic groups: An essential chemical determinant for achieving thiophene-based ligands to distinguish $\beta$-Amyloid or Tau polymorphic aggregates. Chemistry 21: 9072-9082.

Klunk WE, Pettegrew JW, Abraham DJ. 1989. Quantitative evaluation of Congo red binding to amyloid-like proteins with a $\beta$-pleated sheet conformation. J Histochem Cytochem 37: 1273-1281.

Klunk WE, Debnath ML, Pettegrew W. 1994. Development of small molecule probes for the $\beta$-amyloid protein of Alzheimer's disease. Neurobiol Aging 15: 691-698.

Kosik KS, Joachim CL, Selkoe DJ. 1986. Microtubule-associated protein tau $(\tau)$ is a major antigenic component of paired helical filaments in Alzheimer disease. Proc Natl Acad Sci 83: 4044-4048.

Kosik KS, Orecchio LD, Binder L, Trojanowski JQ, Lee VM, Lee G. 1988. Epitopes that span the tau molecule are shared with paired helical filaments. Neuron 1: 817-825.

Landau M, Sawaya MR, Faull KF, Laganowsky A, Jiang L, Sievers SA, Liu J, Barrio JR, Eisenberg D. 2011. Towards a pharmacophore for amyloid. PLoS Biol 9: e1001080.

Larbig G, Pickhardt M, Lloyd DG, Schmidt B, Mandelkow E. 2007. Screening for inhibitors of tau protein aggregation into Alzheimer paired helical filaments: A ligand based approach results in successful scaffold hopping. Curr Alzheimer Res 4: 315-323.

Lasagna-Reeves CA, Castillo-Carranza DL, Guerrero-Muñoz MJ, Jackson GR, Kayed R. 2010. Preparation and characterization of neurotoxic tau oligomers. Biochemistry 49: 10039-10041.

Lasagna-Reeves CA, Castillo-Carranza DL, Sengupta U, Clos AL, Jackson GR, Kayed R. 2011. Tau oligomers impair memory and induce synaptic and mitochondrial dysfunction in wild-type mice. Mol Neurodegener 6: 39.

Lee VM, Balin BJ, Otvos L Jr, Trojanowski JQ. 1991. A68: A major subunit of paired helical filaments and derivatized forms of normal Tau. Science 251: 675-678.

Lee VM, Brunden KR, Hutton M, Trojanowski JQ. 2011. Developing therapeutic approaches to tau, selected kinases, and related neuronal protein targets. Cold Spring Harb Perspect Med 1: a006437.

LeVine H III. 1993. Thioflavine T interaction with synthetic Alzheimer's disease $\beta$-amyloid peptides: Detection of amyloid aggregation in solution. Protein Sci 2: 404-410.

LeVine H III. 2005. Multiple ligand binding sites on $A \beta(1-40)$ fibrils. Amyloid 12: 5-14. 
J.N. Rauch et al.

Li W, Sperry JB, Crowe A, Trojanowski JQ, Smith AB III, Lee VM. 2009. Inhibition of tau fibrillization by oleocanthal via reaction with the amino groups of tau. J Neurochem 110: $1339-1351$.

Lockhart A, Ye L, Judd DB, Merritt AT, Lowe PN, Morgenstern JL, Hong G, Gee AD, Brown J. 2005. Evidence for the presence of three distinct binding sites for the thioflavin T class of Alzheimer's disease PET imaging agents on $\beta$-amyloid peptide fibrils. J Biol Chem 280: $7677-$ 7684.

Maezawa I, Hong HS, Liu R, Wu CY, Cheng RH, Kung MP, Kung HF, Lam KS, Oddo S, Laferla FM, et al. 2008. Congo red and thioflavin-T analogs detect $\mathrm{A} \beta$ oligomers. J Neurochem 104: 457-468.

Mah R, Thomas JR, Shafer CM. 2014. Drug discovery considerations in the development of covalent inhibitors. Bioorg Med Chem Lett 24: 33-39.

Martin L, Latypova X, Terro F. 2011. Post-translational modifications of tau protein: Implications for Alzheimer's disease. Neurochem Int 58: 458-471.

Maruyama M, Shimada H, Suhara T, Shinotoh H, Ji B, Maeda J, Zhang MR, Trojanowski JQ, Lee VM, Ono M, et al. 2013. Imaging of tau pathology in a tauopathy mouse model and in Alzheimer patients compared to normal controls. Neuron 79: 1094-1108.

Melis V, Magbagbeolu M, Rickard JE, Horsley D, Davidson K, Harrington KA, Goatman K, Goatman EA, Deiana S, Close SP, et al. 2015. Effects of oxidized and reduced forms of methylthioninium in two transgenic mouse tauopathy models. Behav Pharmacol 26: 353-368.

Messing L, Decker JM, Joseph M, Mandelkow E, Mandelkow EM. 2013. Cascade of tau toxicity in inducible hippocampal brain slices and prevention by aggregation inhibitors. Neurobiol Aging 34: 1343-1354.

Min SW, Cho SH, Zhou Y, Schroeder S, Haroutunian V, Seeley WW, Huang EJ, Shen Y, Masliah E, Mukherjee C, et al. 2010. Acetylation of tau inhibits its degradation and contributes to tauopathy. Neuron 67: 953-966.

Moe J. 2013. Small-molecule lead identification for inhibition of tau oligomer formation (poster abstract). Alzheimers Dement 9: 891.

Morris M, Knudsen GM, Maeda S, Trinidad JC, Ioanoviciu A, Burlingame AL, Mucke L. 2015. Tau post-translational modifications in wild-type and human amyloid precursor protein transgenic mice. Nat Neurosci 18: 1183-1189.

Mukrasch MD, Biernat J, von Bergen M, Griesinger C, Mandelkow E, Zweckstetter M. 2005. Sites of tau important for aggregation populate $\beta$-structure and bind to microtubules and polyanions. J Biol Chem 280: 24978-24986.

Mukrasch MD, Bibow S, Korukottu J, Jeganathan S, Biernat J, Griesinger C, Mandelkow E, Zweckstetter M. 2009. Structural polymorphism of 441-residue tau at single residue resolution. PLoS Biol 7: e34.

Naiki H, Higuchi K, Hosokawa M, Takeda T. 1989. Fluorometric determination of amyloid fibrils in vitro using the fluorescent dye, thioflavin T1. Anal Biochem 177: 244249.

Necula M, Chirita CN, Kuret J. 2005. Cyanine dye N744 inhibits tau fibrillization by blocking filament extension: Implications for the treatment of tauopathic neurodegenerative diseases. Biochemistry 44: 10227-10237.
Okamura N, Furumoto S, Harada R, Tago T, Yoshikawa T, Fodero-Tavoletti M, Mulligan RS, Villemagne VL, Akatsu H, Yamamoto T, et al. 2013. Novel ${ }^{18}$ F-labeled arylquinoline derivatives for noninvasive imaging of tau pathology in Alzheimer disease. J Nucl Med 54: 1420-1427.

O'Leary JC III, Li Q, Marinec P, Blair LJ, Congdon EE, Johnson AG, Jinwal UK, Koren J III, Jones JR, Kraft C, et al. 2010. Phenothiazine-mediated rescue of cognition in tau transgenic mice requires neuroprotection and reduced soluble tau burden. Mol Neurodegener 5: 45.

Pérez M, Valpuesta JM, Medina M, Montejo de Garcini E, Avila J. 1996. Polymerization of tau into filaments in the presence of heparin: The minimal sequence required for tau-tau interaction. J Neurochem 67: 1183-1190.

Pickhardt M, von Bergen M, Gazova Z, Hascher A, Biernat J, Mandelkow EM, Mandelkow E. 2005. Screening for inhibitors of tau polymerization. Curr Alzheimer Res 2: 219-226.

Pickhardt M, Larbig G, Khlistunova I, Coksezen A, Meyer B, Mandelkow EM, Schmidt B, Mandelkow E. 2007a. Phenylthiazolyl-hydrazide and its derivatives are potent inhibitors of tau aggregation and toxicity in vitro and in cells. Biochemistry 46: 10016-10023.

Pickhardt M, Biernat J, Khlistunova I, Wang YP, Gazova Z, Mandelkow EM, Mandelkow E. 2007b. N-phenylamine derivatives as aggregation inhibitors in cell models of tauopathy. Curr Alzheimer Res 4: 397-402.

Reed MA, Wood TK, Banfield SC, Barden CJ. 2016. Benzofurazan anti-amyloid compounds and methods. U.S. Patent No. 9,328,078, May 3.

Reinke AA, Gestwicki JE. 2011. Insight into amyloid structure using chemical probes. Chem Biol Drug Des 77: 399_ 411.

Roberts BE, Duennwald ML, Wang H, Chung C, Lopreiato NP, Sweeny EA, Knight MN, Shorter J. 2009. A synergistic small-molecule combination directly eradicates diverse prion strain structures. Nat Chem Biol 5: 936-946.

Sato S, Tatebayashi Y, Akagi T, Chui DH, Murayama M, Miyasaka T, Planel E, Tanemura K, Sun X, Hashikawa T, et al. 2002. Aberrant tau phosphorylation by glycogen synthase kinase- $3 \beta$ and JNK3 induces oligomeric tau fibrils in COS-7 cells. J Biol Chem 277: 42060-42065.

Schafer KN, Cisek K, Huseby CJ, Chang E, Kuret J. 2013. Structural determinants of Tau aggregation inhibitor potency. J Biol Chem 288: 32599-32611.

Schneider A, Mandelkow E. 2008. Tau-based treatment strategies in neurodegenerative diseases. Neurotherapeutics 5: 443-457.

Schweers O, Schönbrunn-Hanebeck E, Marx A, Mandelkow E. 1994. Structural studies of tau protein and Alzheimer paired helical filaments show no evidence for $\beta$-structure. J Biol Chem 269: 24290-24297.

Sillen A, Barbier P, Landrieu I, Lefebvre S, Wieruszeski JM, Leroy A, Peyrot V, Lippens G. 2007. NMR investigation of the interaction between the neuronal protein tau and the microtubules. Biochemistry 46: 3055-3064.

Stancu IC, Vasconcelos B, Ris L, Wang P, Villers A, Peeraer E, Buist A, Terwel D, Baatsen P, Oyelami T, et al. 2015. Templated misfolding of Tau by prion-like seeding along neuronal connections impairs neuronal network function and associated behavioral outcomes in Tau transgenic mice. Acta Neuropathol 129: 875-894. 
Tanemura K, Akagi T, Murayama M, Kikuchi N, Murayama O, Hashikawa T, Yoshiike Y, Park JM, Matsuda K, Nakao S, et al. 2001. Formation of filamentous tau aggregations in transgenic mice expressing V337M human tau. Neurobiol Dis 8: 1036-1045.

Taniguchi S, Suzuki N, Masuda M, Hisanaga S, Iwatsubo T, Goedert M, Hasegawa M. 2005. Inhibition of heparininduced tau filament formation by phenothiazines, polyphenols, and porphyrins. J Biol Chem 280: 7614-7623.

Thompson PW, Ye L, Morgenstern JL, Sue L, Beach TG, Judd DJ, Shipley NJ, Libri V, Lockhart A. 2009. Interaction of the amyloid imaging tracer FDDNP with hallmark Alzheimer's disease pathologies. J Neurochem 109: 623-630.

Tóth G, Gardai SJ, Zago W, Bertoncini CW, Cremades N, Roy SL, Tambe MA, Rochet JC, Galvagnion C, Skibinski G, et al. 2014. Targeting the intrinsically disordered structural ensemble of $\alpha$-synuclein by small molecules as a potential therapeutic strategy for Parkinson's disease. PLoS One 9: e87133.

Treventis Corporation. 2015. Preclinical candidate TRV 10 demonstrates significant reduction in both amyloid- $\beta$ and tau toxic aggregates in animal models of Alzheimer's disease (press release).

Tritsch D, Zinglé C, Rohmer M, Grosdemange-Billiard C. 2015. Flavonoids: True or promiscuous inhibitors of enzyme? The case of deoxyxylulose phosphate reductoisomerase. Bioorg Chem 59: 140-144.

Vassar PS, Culling CF. 1959. Fluorescent stains, with special reference to amyloid and connective tissues. Arch Patho 68: $487-498$.

Villemagne VL, Furumoto S, Fodero-Tavoletti MT, Mulligan RS, Hodges J, Harada R, Yates P, Piguet O, Pejoska S, Dore $\mathrm{V}$, et al. 2014. In vivo evaluation of a novel tau imaging tracer for Alzheimer's disease. Eur J Nucl Med Mol Imaging 41: 816-826.

Violet M, Delattre L, Tardivel M, Sultan A, Chauderlier A, Caillierez R, Talahari S, Nesslany F, Lefebvre B, Bonnefoy $\mathrm{E}$, et al. 2014. A major role for Tau in neuronal DNA and RNA protection in vivo under physiological and hyperthermic conditions. Front Cell Neurosci 8: 84.

von Bergen M, Friedhoff P, Biernat J, Heberle J, Mandelkow EM, Mandelkow E. 2000. Assembly of tau protein into Alzheimer paired helical filaments depends on a local
Interactions between MAPT and Small Molecules

sequence motif $\left({ }^{306} \mathrm{VQIVYK}^{311}\right)$ forming $\beta$ structure. Proc Natl Acad Sci 97: 5129-5134.

Wilson DM, Binder LI. 1997. Free fatty acids stimulate the polymerization of tau and amyloid $\beta$ peptides. In vitro evidence for a common effector of pathogenesis in $\mathrm{Alz}$ heimer's disease. Am J Pathol 150: 2181-2195.

Wischik CM, Edwards PC, Lai RY, Roth M, Harrington CR. 1996. Selective inhibition of Alzheimer disease-like tau aggregation by phenothiazines. Proc Natl Acad Sci 93: 11213-11218.

Wischik CM, Harrington CR, Storey JM. 2014. Tau-aggregation inhibitor therapy for Alzheimer's disease. Biochem Pharmacol 88: 529-539.

Wischik CM, Staff RT, Wischik DJ, Bentham P, Murray AD, Storey JM, Kook KA, Harrington CR. 2015. Tau aggregation inhibitor therapy: An exploratory phase 2 study in mild or moderate Alzheimer's disease. J Alzheimers Dis 44: 705-720.

Wobst HJ, Sharma A, Diamond MI, Wanker EE, Bieschke J. 2015. The green tea polyphenol (-)-epigallocatechin gallate prevents the aggregation of tau protein into toxic oligomers at substoichiometric ratios. FEBS Lett 589: $77-83$.

Wolfe LS, Calabrese MF, Nath A, Blaho DV, Miranker AD, Xiong Y. 2010. Protein-induced photophysical changes to the amyloid indicator dye thioflavin T. Proc Natl Acad Sci 107: 16863-16868.

Xia CF, Arteaga J, Chen G, Gangadharmath U, Gomez LF, Kasi D, Lam C, Liang Q, Liu C, Mocharla VP, et al. 2013. $\left[{ }^{18} \mathrm{~F}\right] \mathrm{T} 807$, a novel tau positron emission tomography imaging agent for Alzheimer's disease. Alzheimers Dement 9: 666-676.

Yao J, Gao X, Sun W, Yao T, Shi S, Ji L. 2013. Molecular hairpin: A possible model for inhibition of tau aggregation by tannic acid. Biochemistry 52: 1893-1902.

Ye L, Morgenstern JL, Gee AD, Hong G, Brown J, Lockhart A. 2005. Delineation of positron emission tomography imaging agent binding sites on $\beta$-amyloid peptide fibrils. J Biol Chem 280: 23599-23604.

Zhang W, Arteaga J, Cashion DK, Chen G, Gangadharmath U, Gomez LF, Kasi D, Lam C, Liang Q, Liu C, et al. 2012. A highly selective and specific PET tracer for imaging of tau pathologies. J Alzheimers Dis 31: 601-612. 


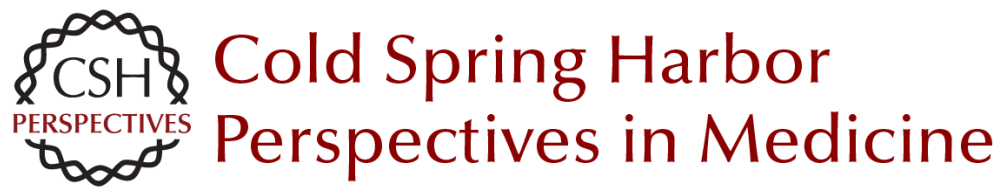

\title{
Interactions between Microtubule-Associated Protein Tau (MAPT) and Small Molecules
}

\author{
Jennifer N. Rauch, Steven H. Olson and Jason E. Gestwicki
}

Cold Spring Harb Perspect Med 2017; doi: 10.1101/cshperspect.a024034 originally published online December 9, 2016

\section{Subject Collection Prion Diseases}

TDP-43 Prions

Takashi Nonaka and Masato Hasegawa

$\alpha$-Synuclein: Multiple System Atrophy Prions Amanda L. Woerman, Joel C. Watts, Atsushi Aoyagi, et al.

Genetics of Synucleinopathies Robert L. Nussbaum

$\beta$-Amyloid Prions and the Pathobiology of Alzheimer's Disease Joel C. Watts and Stanley B. Prusiner

Disease Mechanisms of C9ORF72 Repeat Expansions Tania F. Gendron and Leonard Petrucelli

Chronic Traumatic Encephalopathy: Is Latency in Symptom Onset Explained by Tau Propagation? Joshua Kriegel, Zachary Papadopoulos and Ann C. McKee

Noncerebral Amyloidoses: Aspects on Seeding, Cross-Seeding, and Transmission Gunilla T. Westermark, Marcus Fändrich, Katarzyna Lundmark, et al.

Structural and Chemical Biology of Presenilin Complexes

Douglas S. Johnson, Yue-Ming Li, Martin Pettersson, et al.
Cell Biology and Pathophysiology of $\alpha$-Synuclein Jacqueline Burré, Manu Sharma and Thomas C. Südhof

Molecular Mechanisms of Chronic Wasting

Disease Prion Propagation Julie A. Moreno and Glenn C. Telling

Genetics of Amyotrophic Lateral Sclerosis Mehdi Ghasemi and Robert H. Brown, Jr.

The Genetics of C9orf72 Expansions Ilse Gijselinck, Marc Cruts and Christine Van Broeckhoven

Prion-Like Characteristics of

Polyglutamine-Containing Proteins Margaret M.P. Pearce and Ron R. Kopito

Therapeutic Strategies for Restoring Tau Homeostasis

Zapporah T. Young, Sue Ann Mok and Jason E. Gestwicki

Fused in Sarcoma Neuropathology in Neurodegenerative Disease

Ian R.A. Mackenzie and Manuela Neumann

Experimental Models of Inherited PrP Prion Diseases Joel C. Watts and Stanley B. Prusiner

For additional articles in this collection, see http://perspectivesinmedicine.cshlp.org/cgi/collection/ 